\section{Evaluation of Dosimetric Properties of Handmade Bolus for Megavoltage Electron and Photon Radiation Therapy}

\author{
Endarko Endarko ${ }^{1 * \bullet}$, Siti Aisyah², Chycilia Clara Chandra \\ Carina $^{2}$, Trimawarti Nazara², Gandes Sekartaji², Andreas \\ Nainggolan ${ }^{3}$
}

\begin{abstract}
Background: The use of boluses for radiation therapy is very necessary to overcome the problem of sending inhomogeneous doses in the target volume due to irregularities on the surface of the skin. The bolus materials for radiation therapy need to be evaluated.
\end{abstract}

Objective: The present study aims to evaluate some handmade boluses for megavoltage electron and photon radiation therapy. Several dosimetric properties of the synthesized boluses, including relative electron density (RED), transmission factor, mass attenuation coefficient, percentage depth dose (PDD), and percentage surface dose (PSD) were investigated.

Material and Methods: In this experimental study, we evaluated natural rubber, silicone rubber mixed either with aluminum or bismuth, paraffin wax, red plasticine, and play-doh as soft tissue equivalent. CT-simulator, in combination with ECLIPSE software, was used to determine bolus density. Meanwhile, Linear Accelerator (Linac) Clinac iX (Varian Medical Systems, Palo Alto), solid water phantom, and Farmer ionization chamber were used to measure and analyze of dosimetric properties.

Results: The RED result analysis has proven that all synthesized boluses are equivalent to the density of soft tissue such as fat, breast, lung, and liver. The dosimetric evaluation also shows that all synthesized boluses have a density similar to the density of water and can increase the surface dose with a value ranging from $6-20 \%$ for electron energy and $30-50 \%$ for photon energy.

Conclusion: In general, all synthesized boluses have an excellent opportunity to be used as an alternative tissue substitute in the surface area of the body when using megavoltage electron and photon energy.

Citation: Endarko E, Aisyah S, Carina CCC, Nazara T, Sekartaji G, Nainggolan A. Evaluation of Dosimetric Properties of Handmade Bolus for Megavoltage Electron and Photon Radiation Therapy. J Biomed Phys Eng. 2021;11(6):735-746. doi: 10.31661/jbpe.v0i0.2004-1108.

\section{Keywords}

Bolus; Linac; Radiotherapy; Dosimetry; Radiation; Soft Tissue Injuries

\section{Introduction}

$\mathrm{T}$ he protection of healthy tissue in radiation therapy or radiotherapy that uses external beam ionizing radiation to deliver the optimal dose of either the electron, photon, or a combination of the two in the target volume has become the primary consideration in treatment of patients [1-4]. Superficial cancer lesions are challenging to irradiate due to the dose build-up effect from megavoltage X-ray radiation physics [4]. The high energy photon beams characteristically have
${ }^{1} \mathrm{PhD}$, Department of Physics, Institut Teknologi Sepuluh Nopember, Kampus ITS - Sukolilo Surabaya 60111, East Java, Indonesia

${ }^{2} \mathrm{BSc}$, Department of

Physics, Institut Teknolo-

gi Sepuluh Nopember,

Kampus ITS - Sukolilo

Surabaya 60111, East

Java, Indonesia

${ }^{3} \mathrm{MSc}$, Mochtar Riady

Comprehensive Cancer

Center Siloam Hospi-

tals Semanggi, Jakarta,

Indonesia

Corresponding author:

Endarko Endarko

Department of Physics,

Instut Teknologi Sepuluh

Nopember (ITS) Kampus

ITS - Sukolilo Surabaya

60111, East Java, Indonesia

E-mail: endarko@gmail. com

Received: 20 April 2020 Accepted: 10 June 2020 
a lower dose at the surface and a higher dose (dose maximum) at depth [1]. Meanwhile, irradiation of electron beams to a patient's surfaces with surgical imperfections could lead to an inhomogeneous dose distribution in underlying tissue [5].

In common practice, to solve the problem of dose delivery inhomogeneity in the target volume due to the irregularities of the skin surface, a material is usually added as a compensator for the missing tissue called a bolus [1-3, 6-14]. The primary purpose of adding a bolus to radiotherapy is to increase the surface dose $[1,14]$ and make the body surface anatomy as similar to a water phantom as possible so that a more homogeneous dose distribution is obtained [5].

The material used in making boluses must have some specific properties such as easy producibility, flexibility, good visibility, and it should be non-sticky, non-toxic, inexpensive and has a computed tomography number in the range of 130 to $160 \mathrm{HU}[3,15]$. Making bolus with material as tissue compensator is not easy to meet in the clinical standard. However, some previous studies have reported the use of materials that are similar to the tissue, such as aquaplast (Qfix, Orfit), gels, superflab, elasto-gel pad, dental wax, rayon blend, paraffin granules, and polypropylene $[1-3,7,8$, $10,12,14,16-22]$. The materials such as aquaplast (Qfix, Orfit), superflab, elasto-gel pad, and polypropylene are very rarely found in Indonesia and must be imported from abroad. As an alternative, we use silicone rubber, natural rubber, red plasticine, paraffin wax, and playdoh in this study.

Silicone and natural rubbers are biomaterials that have properties such as bio durability, biocompatibility, and serializability. This material is already widely used in medical applications such as catheters, cardiac pacemaker leads, diaphragms, artificial skin, and blood pressure cuff coil [23]. Meanwhile, play-doh and red plasticine are commonly used in hospitals as bolus material for radiotherapy as in
Dr. Soetomo Hospital, Surabaya, and MRCCC Siloam Semanggi, Jakarta, Indonesia, respectively.

In the present study, the dosimetric properties for bolus materials such as natural rubber, the mixture of silicone rubber with bismuth or aluminum, paraffin wax, red plasticine, and play-doh were evaluated. Some analyses and characterizations are also investigated, namely relative electron density (RED), transmission factor, mass attenuation coefficient (MAC), percentage depth dose (PDD) curve, and percentage surface dose (PSD).

\section{Material and Methods}

\section{Bolus Fabrication}

In this experimental study, we maintained all boluses with the same size of dimension 11 $\times 11 \mathrm{~cm}^{2}$ for various thicknesses, namely 0.5 , 1 , and $1.5 \mathrm{~cm}$. For the synthesized bolus from natural rubber (NR), it was fabricated with a mixture of $195 \mathrm{~mL}$ of $\mathrm{NR}$ and $5 \mathrm{~mL}$ of formic acid and stirred for $5 \mathrm{~s}$ and then poured into an acrylic mold. Furthermore, for the synthesized bolus from silicone rubber (SR), we used two variations, a silicone rubber mixed with bismuth and a silicone rubber mixed with aluminum (Al).

For silicone rubber mixed with bismuth, the bolus was synthesized with a mixture of SR, bismuth, and catalyst, with a value of $670 \mathrm{~mL}$, $1 \mathrm{~g}$, and $14 \mathrm{~mL}$, respectively. A mixture of SR and bismuth was stirred for $10 \mathrm{~min}$ and then added the catalyst to be stirred for another 3 min, after getting poured into a mold.

Furthermore, for bolus with a mixture of SR and $\mathrm{Al}, 350 \mathrm{~mL}$ of $\mathrm{SR}$ and $1 \mathrm{~g}$ of aluminum were mixed evenly, and then $6 \mathrm{~mL}$ of catalyst was added while being stirred until thoroughly mixed, then poured into a mold.

Meanwhile, for the synthesized bolus from red plasticine and play-doh, the materials were easily formed in the mold according to the predetermined size. In contrast, for bolus made from paraffin wax, the material must be 
melted first and then poured into the mold.

\section{Relative Electron Density (RED)}

The density test was carried out at the MRCC Siloam Hospital, Semanggi, Jakarta. The density value can be obtained by using a HU to RED conversion value. RED values for all boluses were scanned using the CT-simulator, as shown in Figure 1. Tomographic images were then taken using the axial scanning method that has been regulated by regulating tube voltage, tube current, and slice thickness with values $20 \mathrm{kV}, 285 \mathrm{~mA}$, and $5 \mathrm{~mm}$, respectively.

Then the results of the tomographic images were processed in the treatment planning system (TPS) by choosing three regions of interest (ROI) in a square shape horizontally to determine the CT-Number using ECLIPSE software. Region of interest can be done by positioning the sample in axial or coronal directions so that RED can be calculated with CT-Number data using the following formula [24]:

$$
\begin{aligned}
& \rho=1.052+0.00048 N_{C T}, N_{C T}>100 \\
& \rho=1.000+0.001 N_{C T}, N_{C T}<100
\end{aligned}
$$

Where $\rho$ and NCT are the values of RED and CT-number, respectively.

\section{Dosimetry Characterization}

For dosimetric characterization, all boluses were tested using Linac Clinac iX (Varian
Medical Systems, Palo Alto) at MRCC Siloam Hospital, Semanggi, Jakarta, Indonesia using both electron and photon beams. Dosimetry test was performed to obtain the value of absorbed dose, transmission factor, mass attenuation coefficient (MAC), percentage depth dose (PDD) curve, and percentage surface dose (PSD).

Dosimetric evaluation by electron beam was done by the energies of 6,9 , and $12 \mathrm{MeV}$. Measurements were carried out with a parallel plate ionization chamber PPC40 at the reference depth at 1.3, 2 and $2.9 \mathrm{~cm}$, respectively, at a distance of $100 \mathrm{~cm}$ from the source with a dose rate of $100 \mathrm{MU} / \mathrm{min}$ with an area of irradiation of $10 \times 10 \mathrm{~cm}^{2}$ and an additional applicator of $10 \times 10 \mathrm{~cm}^{2}$. In addition, for the dosimetry test using the photon beam, we used photon beams with energies of 6 and $10 \mathrm{MV}$ and a dose rate of $100 \mathrm{MU} / \mathrm{min}$. The data was measured using field area irradiation of 10 $\times 10 \mathrm{~cm}^{2}$ and the source to surface distance (SSD) of $100 \mathrm{~cm}$. Henceforth, the bolus transmission factor was measured using a Farmer ionization chamber of 0.65 cc (Type FC655). For each measurement, the ionization chamber was positioned at maximum depth. Simultaneously, bolus was placed onto the top of the phantom surface for $6 \mathrm{MV}$ energy at $1.5 \mathrm{~cm}$, whereas for $10 \mathrm{MV}$ at $2.3 \mathrm{~cm}$. All absorbed dose measurement data were carried out using TRS 398 [25].

In this study, the value of the transmission
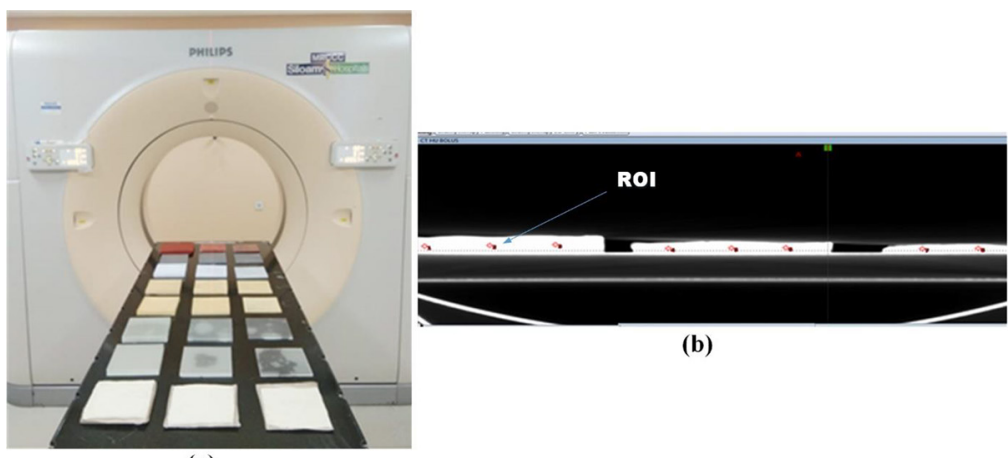

(b)

(a)

Figure 1: The process of determining bolus density: a) scanning bolus and b) selecting points of region of interest (ROI) in ECLIPSE software to determine the Computed Tomography (CT) number. 
factor was obtained from the ratio of absorbed doses with and without bolus. The transmission factor can be calculated using the equation as follows [3]:

Transmission $_{\text {sample }}=100 \times\left(\right.$ dose $_{\text {sample }} /$ dose $\left._{\text {open field }}\right)$

The MAC of bolus materials can be calculated using the equation as follows [26, 27]:

$$
\ln \left(\frac{I}{I_{0}}\right)=-\mu_{m e f f} X_{b} f \rho_{b}
$$

Where $I / I_{0}$ is a transmission factor due to the light emitted into the bolus, and $x_{b}$ is the bolus thickness $(\mathrm{cm}), \rho_{b}$ is the bolus density $\left(\mathrm{g} / \mathrm{cm}^{3}\right), \mu_{\text {meff }}$ is the effective mass attenuation coefficient $\left(\mathrm{cm}^{2} / \mathrm{g}\right)$, and $\mathrm{f}$ is a correction factor obtained from the bolus as a function of thickness.

PDD values were obtained using the help of ECLIPSE software. The tested boluses were placed on a $1 \mathrm{~cm} 40 \mathrm{slab}$ virtual phantom using a point dose. Point dose is pulled down from the phantom surface to $10 \mathrm{~cm}$ to obtain the PDD curve. The PDD value can be calcu- lated using equation (5) [28].

$$
P D D=\left(\frac{D_{d}}{D_{0}}\right) \times 100 \%
$$

Where $D_{d}$ and $D_{0}$ are the absorbed dose at any depth and the reference depth, respective1y. The value of the surface dose or PSD was determined using the ECLIPSE software at TPS. The surface dose was obtained by creating a virtual phantom and positioning the detector at a point on the surface and maximum depth.

\section{Results}

Figure 2 shows the RED for all of the synthesized boluses for various thicknesses and source energies with a value ranging from 0.75 to 1.14. Based on Figure 2, all bolus thickness variations made met the RED value for lung tissue. In contrast, boluses with a thickness of 1 and $1.5 \mathrm{~cm}$ showed RED values that fall within the soft tissue range, such as the lungs, breasts, liver muscles, and even water.

The summary of the absorbed doses for

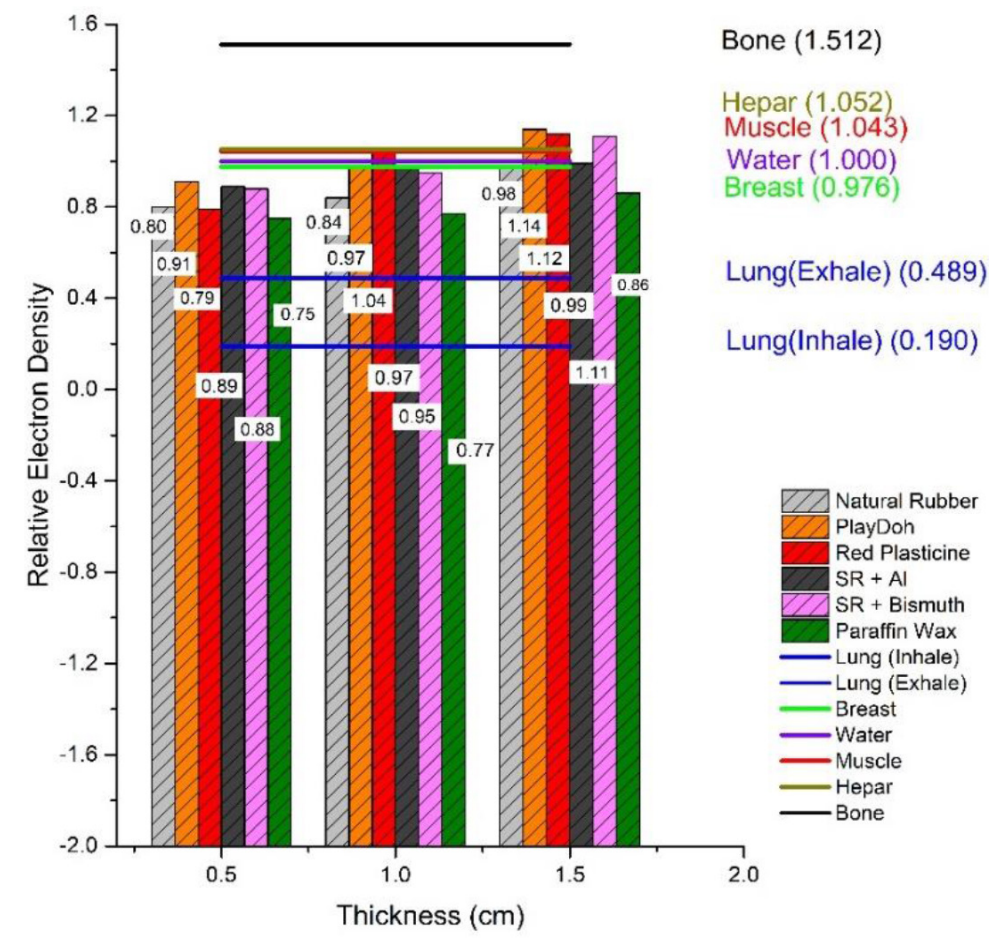

Figure 2: The relative electron density (RED) as a function of thickness for all the synthesized boluses compared to some REDs of human soft tissue. 
all of the synthesized boluses is presented in Table 1. It can be observed that the absorbed dose for all of the boluses with all energies of photons have generally increased compared to the absorbed doses without bolus for any reference depth. Meanwhile, electron energies have various absorbed doses depending on the thickness and the material of bolus compared to absorbed doses without bolus.

When the value of the absorbed dose between bolus and without bolus is compared, the value of the transmission factor can be obtained. The transmission factors for all boluses are summarized in Table 2. Table 2 contains a comparison of the transmission factors for each thickness of the bolus and each energy. It can be analyzed that the value of the transmission factor will decrease in line with the increase in bolus thickness. Overall, the transmission factor produced from the bolus for the photon and electron beams is in the range between 0.975-1.008 and 0.21-1.054, respectively. In addition, Table 2 shows that the transmission factor of the synthesized bolus from natural rubber, play-doh, and paraffin wax with a thickness of $0.5 \mathrm{~cm}$ at $12 \mathrm{MeV}$ has a value of 1 , it means that the bolus can transmit the radiation energy intensity equal to the intensity of the source.

The calculation of the mass attenuation coefficient (MAC) for all boluses is presented in Table 3. The MAC for all bolus thicknesses and all energy variations will increase with increasing thickness of bolus.

The following result is the PDD for all bolus thicknesses. The PDD curves for all the

Table 1: The absorbed doses of all synthesized boluses for various energies of electron and photon beams.

\begin{tabular}{|c|c|c|c|c|c|c|c|}
\hline \multirow{3}{*}{ Material } & \multirow{3}{*}{$\begin{array}{l}\text { Thickness } \\
\text { (cm) }\end{array}$} & \multirow{3}{*}{$\begin{array}{l}\text { Physical Den- } \\
\text { sity }\left(\mathbf{g} / \mathrm{cm}^{3}\right)\end{array}$} & \multicolumn{5}{|c|}{ Absorbed Dose (Gy) at reference depth $\left(Z_{\text {ref }}\right)$} \\
\hline & & & \multicolumn{2}{|c|}{ Photon Beam } & \multicolumn{3}{|c|}{ Electron Beam } \\
\hline & & & $6 \mathrm{MV}$ & $10 \mathrm{MV}$ & $6 \mathrm{MeV}$ & $9 \mathrm{MeV}$ & $12 \mathrm{MeV}$ \\
\hline Without Bolus & & & 1.00 & 0.91 & 0.95 & 0.96 & 0.92 \\
\hline \multirow{3}{*}{ Paraffin Wax } & 0.5 & 0.74 & 1.01 & 0.92 & 1.00 & 0.94 & 1.00 \\
\hline & 1 & 0.82 & 1.00 & 0.89 & 0.99 & 1.00 & 0.93 \\
\hline & 1.5 & 0.87 & 0.99 & 0.91 & 0.80 & 0.85 & 0.81 \\
\hline \multirow{3}{*}{ Red Plasticine } & 0.5 & 0.88 & 1.00 & 0.92 & 0.98 & 0.62 & 0.99 \\
\hline & 1 & 1.00 & 0.99 & 0.91 & 0.59 & 0.99 & 0.97 \\
\hline & 1.5 & 1.13 & 0.98 & 0.90 & 0.20 & 0.95 & 0.88 \\
\hline \multirow{3}{*}{ PlayDoh } & 0.5 & 0.75 & 1.00 & 0.92 & 0.98 & 0.75 & 1.00 \\
\hline & 1 & 0.84 & 1.00 & 0.91 & 0.84 & 1.00 & 1.01 \\
\hline & 1.5 & 0.90 & 0.98 & 0.90 & 0.42 & 1.01 & 1.01 \\
\hline \multirow{3}{*}{ Natural rubber } & 0.5 & 0.93 & 1.01 & 0.92 & 1.00 & 1.00 & 1.00 \\
\hline & 1 & 0.98 & 1.01 & 0.92 & 1.01 & 1.01 & 1.01 \\
\hline & 1.5 & 1.16 & 1.01 & 0.92 & 1.01 & 1.02 & 1.01 \\
\hline \multirow{3}{*}{ SR + Aluminium } & 0.5 & 0.92 & 1.01 & 0.92 & 1.02 & 0.82 & 0.99 \\
\hline & 1 & 0.99 & 0.99 & 0.91 & 0.85 & 1.00 & 0.98 \\
\hline & 1.5 & 1.06 & 0.99 & 0.91 & 0.56 & 0.97 & 0.91 \\
\hline \multirow{3}{*}{ SR + Bismuth } & 0.5 & 0.95 & 1.00 & 0.92 & 0.99 & 0.81 & 1.00 \\
\hline & 1 & 1.05 & 1.00 & 0.91 & 0.87 & 1.00 & 1.01 \\
\hline & 1.5 & 1.10 & 0.98 & 0.91 & 0.52 & 1.01 & 0.97 \\
\hline
\end{tabular}

SR: Silicone rubber 
Table 2: Transmission factors of all synthesized boluses for various energies of electron and photon beams.

\begin{tabular}{|c|c|c|c|c|c|c|c|}
\hline \multirow{3}{*}{ Material } & \multirow{3}{*}{$\begin{array}{l}\text { Thickness } \\
\text { (cm) }\end{array}$} & \multirow{3}{*}{$\begin{array}{l}\text { Physical Den- } \\
\text { sity }\left(\mathbf{g} / \mathrm{cm}^{3}\right)\end{array}$} & \multicolumn{5}{|c|}{ Transmission Factor (\%) } \\
\hline & & & \multicolumn{2}{|c|}{ Photon Beam } & \multicolumn{3}{|c|}{ Electron Beam } \\
\hline & & & $6 \mathrm{MV}$ & $10 \mathrm{MV}$ & $6 \mathrm{MeV}$ & $9 \mathrm{MeV}$ & $12 \mathrm{MeV}$ \\
\hline \multirow{3}{*}{ Paraffin Wax } & 0.5 & 0.74 & 1.005 & 1.006 & 1 & 1 & 1.01 \\
\hline & 1 & 0.82 & 1.002 & 0.979 & 1.05 & 1.04 & 1.01 \\
\hline & 1.5 & 0.87 & 0.991 & 1.001 & 0.85 & 0.97 & 0.97 \\
\hline \multirow{3}{*}{ Red Plasticine } & 0.5 & 0.88 & 1.002 & 1.006 & 1.031 & 1.024 & 0.998 \\
\hline & 1 & 0.998 & 0.986 & 0.996 & 0.617 & 0.87 & 0.926 \\
\hline & 1.5 & 1.13 & 0.975 & 0.987 & 0.21 & 0.636 & 0.808 \\
\hline \multirow{3}{*}{ Natural rubber } & 0.5 & 0.75 & 1.006 & 1.006 & 1.056 & 1.024 & 0.998 \\
\hline & 1 & 0.84 & 1.006 & 1.007 & 0.992 & 0.993 & 0.995 \\
\hline & 1.5 & 0.9 & 1.005 & 1.008 & 1.175 & 1.06 & 1.033 \\
\hline \multirow{3}{*}{ PlayDoh } & 0.5 & 0.93 & 1.002 & 1.005 & 1 & 1,011 & 0.998 \\
\hline & 1 & 0.98 & 0.995 & 1.002 & 0.884 & 0.976 & 0.97 \\
\hline & 1.5 & 1.16 & 0.981 & 0.994 & 0.448 & 0.774 & 0.877 \\
\hline \multirow{3}{*}{$\mathrm{SR}+\mathrm{Al}$} & 0.5 & 0.920 & 0.99 & 1.01 & 1 & 1 & 1 \\
\hline & 1 & 0.991 & 0.99 & 1.00 & 0.900 & 0.981 & 0.975 \\
\hline & 1.5 & 1.061 & 0.99 & 1.00 & 0.595 & 0.846 & 0.918 \\
\hline \multirow{3}{*}{ SR + Bismuth } & 0.5 & 0.954 & 1.001 & 1.006 & 1.04 & 1.04 & 1.01 \\
\hline & 1 & 1.048 & 0.995 & 0.998 & 0.92 & 0.98 & 0.98 \\
\hline & 1.5 & 1.101 & 0.983 & 0.986 & 0.55 & 0.85 & 0.92 \\
\hline
\end{tabular}

SR: Silicone rubber, AL: Aluminum

synthesized boluses irradiated by an electron beam with different energies are shown in Figure 3. Moreover, it can be seen in Figure 3 that all boluses could shift the peak of the curve $\left(Z_{\max }\right)$ towards the surface for bolus thicknesses of $0.5,1$, and $1.5 \mathrm{~cm}$. Increasing the thickness of each material affects the build-up area. Besides, it is also seen that the thicker bolus causes the percentage of the dose depth to get closer to the surface at an electron beam energy of $6 \mathrm{MeV}$.

PDDs of all the synthesized boluses irradiated by photon beam energies are shown in Figure 4. It can be observed that photon energy, when passing through the phantom, produces a surface dose, a build-up dose, and a maximum dose. All bolus materials with a thickness of $1.5 \mathrm{~cm}$ have no build-up area for 6 MV photon beam when compared to the PDD curve for those without boluses.

The PSD for all boluses can be determined through the PDD curve obtained from Figures 3 and 4 to find out how much dose has reached the surface when given additional boluses. The effect of using bolus material to increase the percentage of a surface dose is documented in Figure 5.

Figure 5 contains all data on the percentage of surface dose irradiated by both electron and photon beams. It can be observed that all the synthesized boluses could increase the dose to the surface for all energies of both electron and photon beams as well as for all bolus thicknesses in compared to without boluses. The increasing value of the PSD for electron beam energy ranges from 6-20\%, while photon energy is even more significant, namely around $30-50 \%$. 
Handmade Bolus

Table 3: The mass attenuation coefficient of all synthesized boluses for various energies of electron and photon beams.

\begin{tabular}{|c|c|c|c|c|c|c|c|}
\hline \multirow{3}{*}{ Material } & \multirow{3}{*}{$\begin{array}{l}\text { Thickness } \\
\text { (cm) }\end{array}$} & \multirow{3}{*}{$\begin{array}{c}\text { Physical Den- } \\
\text { sity }\left(\mathbf{g} / \mathrm{cm}^{3}\right)\end{array}$} & \multicolumn{5}{|c|}{ Mass attenuation coefficient $\left(\mathrm{cm}^{2} / \mathrm{g}\right)$} \\
\hline & & & \multicolumn{2}{|c|}{ Photon Beam } & \multicolumn{3}{|c|}{ Electron Beam } \\
\hline & & & $6 \mathrm{MV}$ & $10 \mathrm{MV}$ & $6 \mathrm{MeV}$ & $9 \mathrm{MeV}$ & $12 \mathrm{MeV}$ \\
\hline \multirow{3}{*}{ Paraffin Wax } & 0.5 & 0.74 & -0.0154 & -0.0159 & 0.0329 & 0.0133 & 0.0067 \\
\hline & 1 & 0.82 & -0.0032 & 0.0265 & 0.0595 & 0.0478 & 0.0121 \\
\hline & 1.5 & 0.87 & 0.0066 & -0.0004 & -0.2802 & -0.0525 & -0.0525 \\
\hline \multirow{3}{*}{ Red Plasticine } & 0.5 & 0.88 & -0.0044 & -0.0134 & -0.0709 & -0.0546 & 0.0057 \\
\hline & 1 & 0.998 & 0.0138 & 0.0038 & 0.487 & 0.1411 & 0.0781 \\
\hline & 1.5 & 1.13 & 0.0151 & 0.0076 & 0.9284 & 0.2698 & 0.1266 \\
\hline \multirow{3}{*}{ Natural rubber } & 0.5 & 0.75 & -0.0160 & -0.0157 & -0.1318 & -0.0579 & 0.004 \\
\hline & 1 & 0.84 & -0.0073 & -0.0083 & -0.0754 & -0.0382 & -0.0069 \\
\hline & 1.5 & 0.9 & -0.0035 & -0.0055 & -0.0425 & -0.0293 & -0.0061 \\
\hline \multirow{3}{*}{ PlayDoh } & 0.5 & 0.93 & -0.0035 & -0.0115 & -0.0682 & -0.0238 & 0.0268 \\
\hline & 1 & 0.98 & 0.0055 & -0.0022 & 0.1255 & 0.0248 & 0.0308 \\
\hline & 1.5 & 1.16 & 0.0108 & 0.0037 & 0.4653 & 0.1488 & 0.0762 \\
\hline \multirow{3}{*}{$\mathrm{SR}+\mathrm{Al}$} & 0.5 & 0.920 & -0.003 & -0.0123 & -0.1571 & -0.0853 & -0.024 \\
\hline & 1 & 0.991 & 0.004 & 0.0015 & 0.1080 & 0.0197 & 0.0259 \\
\hline & 1.5 & 1.061 & 0.0098 & 0.0081 & 0.3472 & 0.1118 & 0.0572 \\
\hline \multirow{3}{*}{ SR + Bismuth } & 0.5 & 0.954 & -0.003 & -0.0123 & -0.1571 & -0.0853 & -0.024 \\
\hline & 1 & 1.048 & 0.004 & 0.0015 & 0.1080 & 0.0197 & 0.0259 \\
\hline & 1.5 & 1.101 & 0.0098 & 0.0081 & 0.3472 & 0.1118 & 0.0572 \\
\hline
\end{tabular}

SR: Silicone rubber, AL: Aluminum

\section{Discussion}

Bolus density values made must have a value equivalent to human tissue. Figure 2 shows the values of relative electron density for all of the synthesized boluses compared to the human tissues $[29,30]$. It can be analyzed from Figure 2 that the value of RED for each bolus is different, which is due to the constituent material and bolus thickness. In general, the RED value of a bolus increases with increasing the thickness of the bolus. It appears in Figure 2 that all boluses have a value below the RED value of the bone. It is due to the fact that bones are composed of mineral phase, organic phase, hydroxyapatite $\left(\mathrm{Ca}_{10}\left(\mathrm{PO}_{4}\right)_{6}(\mathrm{OH})_{2}\right)$, and water [31]. It also shows that all boluses have the RED values in soft tissues such as water, muscles, fat, and breasts. Soft tissue materi- als such as muscles and breasts generally have constituent atoms such as hydrogen $(\mathrm{H})$, carbon $(\mathrm{C})$, oxygen $(\mathrm{O})$, nitrogen $(\mathrm{N})$, phosphorus $(\mathrm{P})$, sulfur $(\mathrm{S})$, chlorine $(\mathrm{Cl})$, sodium $(\mathrm{Na})$, potassium $(\mathrm{K})$ and Phosphorus $(\mathrm{P})$ [32].

Most of SR is composed of silicon material, which is more flexible compared to other polymers [22]. In a previous study, Gede Jaya reported that SR bolus had a density of 0.860 $\mathrm{g} / \mathrm{cm}^{3}$ [12], whereas, in this study, bismuth or aluminum was added to the SR sample. It seems that the addition of the density value is because of the addition of the material into $\mathrm{SR}$, as shown in Table 1.

The bolus of natural rubber consists of $\mathrm{C}_{5} \mathrm{H}_{8}$ polymer bonds that due to the water content $\left(\mathrm{H}_{2} \mathrm{O}\right)$, it has the similarity of constituent material with soft tissue [7]. The paraffin wax 

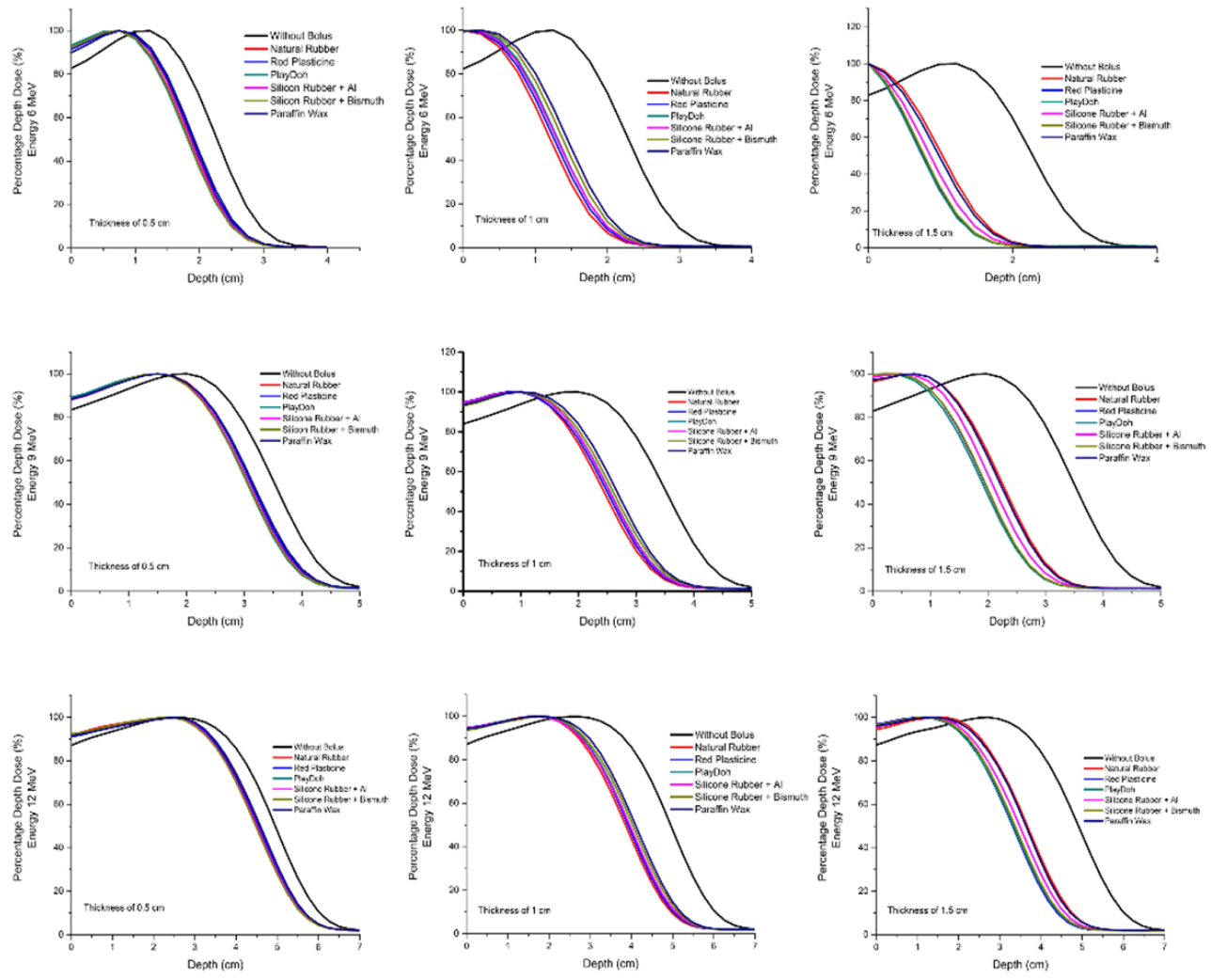

Figure 3: Percentage depth doses (PDD) of all synthesized boluses for various energies of electron beam.
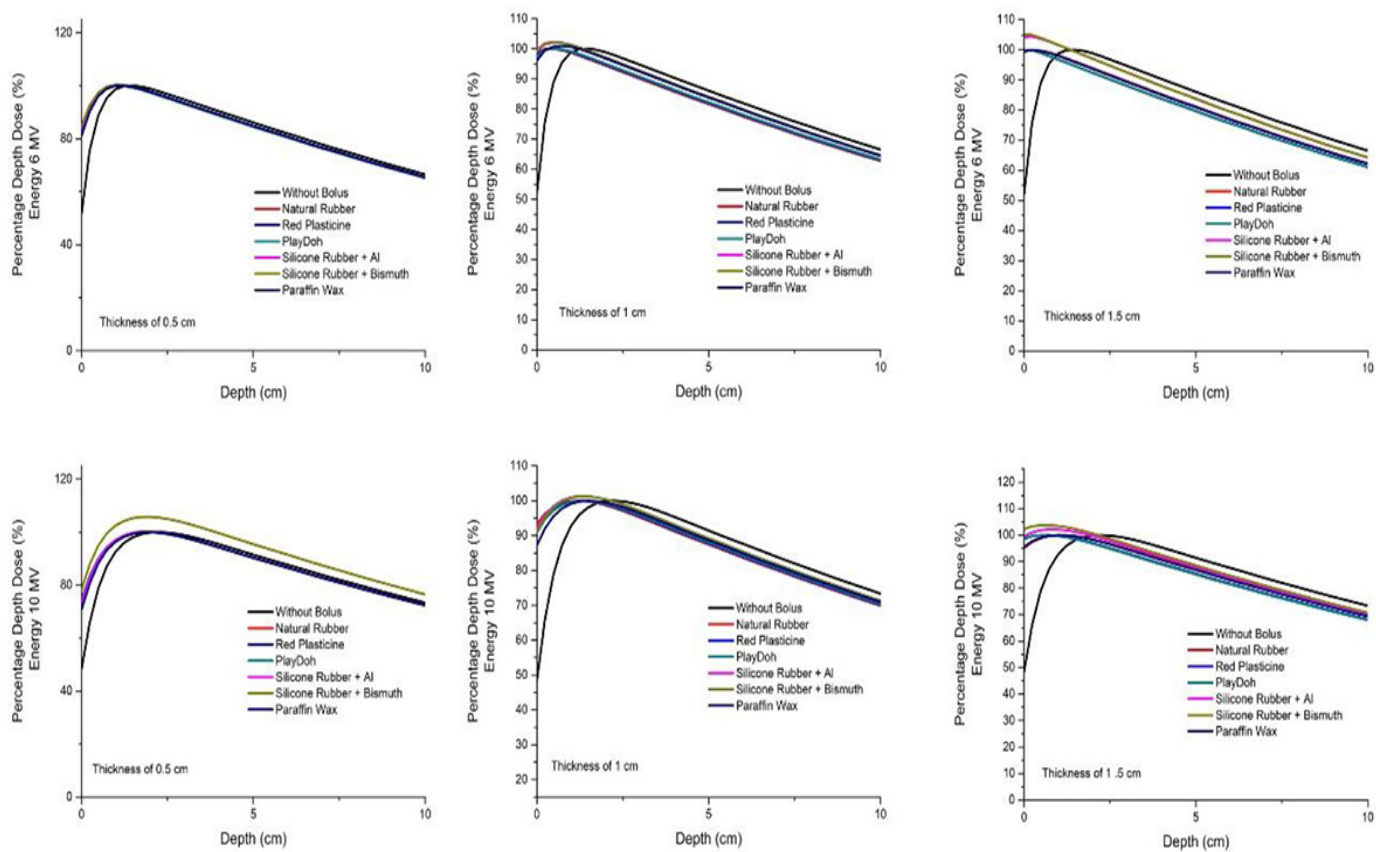

Figure 4: Percentage depth dose (PDD) of all synthesized boluses for various energies of photon beam. 

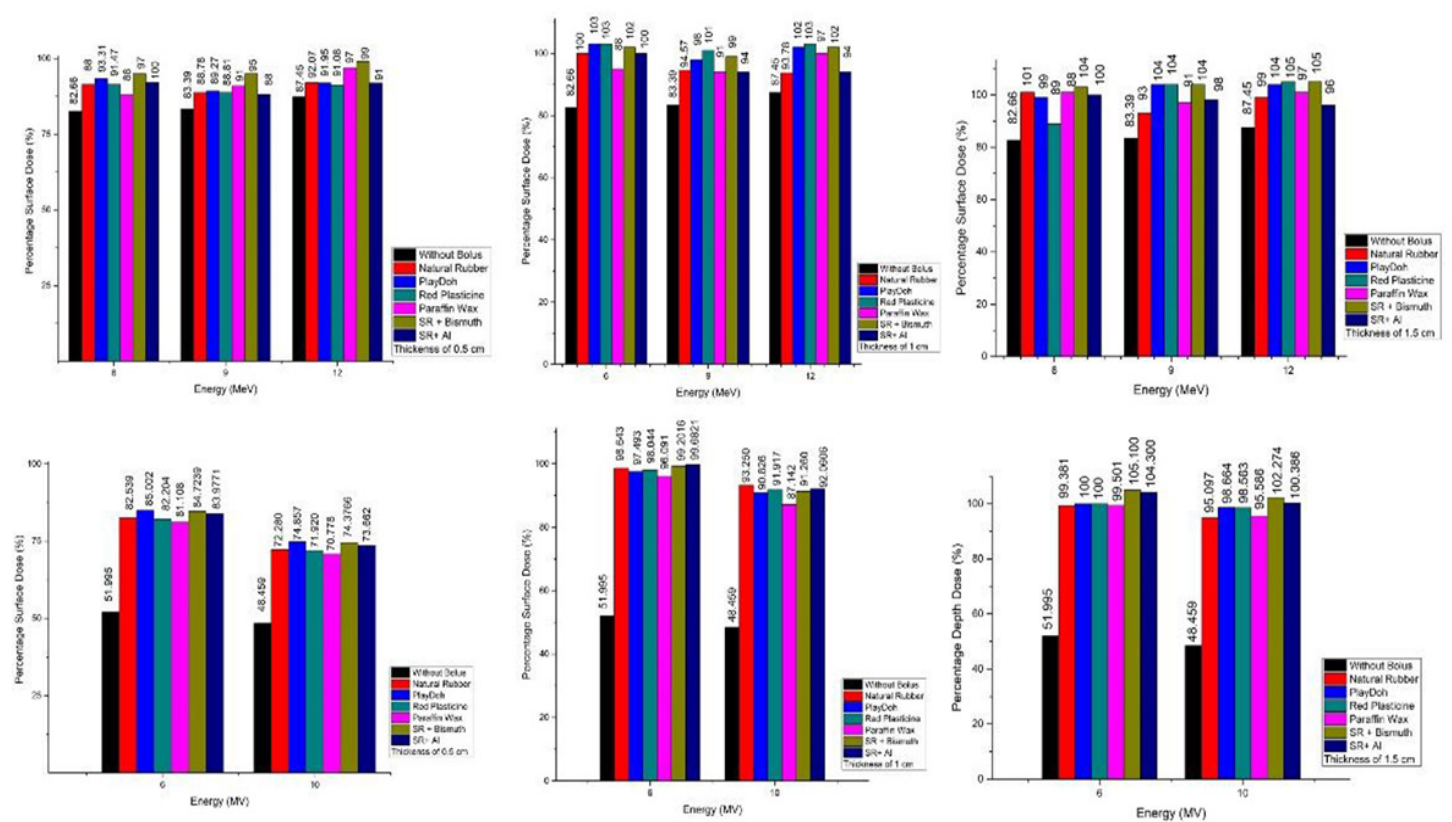

Figure 5: Percentage of surface dose (PSD) of all synthesized boluses for various energies of electron and photon beams.

bolus is composed of organic polymer bonds, namely $\mathrm{C}_{5} \mathrm{H}_{8}$ that due to water content $\left(\mathrm{H}_{2} \mathrm{O}\right)$, it has the similarity of constituent material with soft tissue as well. For Play-Doh itself, it is made from flour, salt, boric acid, and water [33].

There is difference in absorbed dose values when a bolus is used or not, as shown in Table 1. It is due to the interaction of electrons with the material, resulting in elastic and inelastic scattering on the bolus. Absorbed dose value decreases with increasing bolus thickness compared to without bolus because a bolus with a small thickness scatters electrons more easily compared to thicker boluses [34]. Based on data in Table 2, the increasing thickness of the bolus decreases the transmission factor [3]. The greater the energy supplied, the higher the transmission factor. This is the same as research conducted by Kumar et al, [35]. A transmission factor of greater than 1 indicates that the intensity of the photon is transmitted entirely, and there is an amplification due to scattering [34].

The thickness of bolus material affects the process of absorption of radiation and which is passed on. The thicker bolus has bonds between atoms that are stronger. When interacting with the radiation beam, it will cause more energy to be absorbed and less energy to be transmitted.The transmission value of photon energy increases with an increase in energy that is consistent with previous research [36].

For the electron energy, all boluses with a thickness of $1 \mathrm{~cm}$ have absorbent properties like the study conducted by Montaseri et al, [24]. At a thickness of $1.5 \mathrm{~cm}$, the natural rubber bolus cannot be used as an absorber but clinical bolus (play-doh and wax night), SR + $\mathrm{Al}$, and SR + Bismuth can be stated as highly absorbent materials because the transmission factor value is less than 0.98 [24] or less than 1 [37].

In addition to the absorption dose and transmission factor of the bolus, we calculated the value of the mass attenuation coefficient of the bolus to validate the dosimetric property of the material further. The mass attenuation coefficient of the energies of 6 to $10 \mathrm{MV}$ used in this study do not differ much. It is in accordance with a previous study [38], where the difference in value between radiation energy does 
not significantly influence the mass attenuation coefficient value. Meanwhile, the negative value of the mass attenuation coefficient is due to Rayleigh scattering, where the intensity of the incoming photon will be the same as the photon after collision [28]. The value of the attenuation coefficient will decrease with increasing electron energy for boluses with thicknesses of 1 and $1.5 \mathrm{~cm}$; this is in accordance with research conducted by Paliwal et al, and Tanir et al, [37, 38]. Conversely, the addition of energy causes an increase in the value of the mass attenuation coefficient of all boluses at a thickness of 0.5 in all energies of 6, 9, and $12 \mathrm{MeV}$.

The phenomenon of maximum peak shifted to the surface can be explained from the transmission value data of each bolus (Table 1), from the obtained data, the increasing bolus thickness makes it more difficult for energy to pass through due to the increase of the density of bolus. It means that the ionization interaction between energy and material atoms will produce much scattering, causing energy loss because it is transferred in the form of kinetic energy. Tremethick reports that as the thickness of a bolus increases, the PDD curve shifts more towards the surface, i.e. the bolus material is able to raise the dose to the surface at 9 $\mathrm{MeV}$ energy [39].

A further phenomenon is that the PDD dose slowly decreases with depth after exiting the maximum dose depth at all bolus thicknesses; in accordance with the previous study by Khan and Gibbons, it can be interpreted that boluses 1 and $1.5 \mathrm{~cm}$ thick are suitable for tumors or cancers in the surface area or near the surface [28]. The addition of energy also has an effect on the PDD curve. It can be observed at $12 \mathrm{MeV}$, energy increasingly away from the zero value because of the side effects of the Bremsstrahlung interaction. This interaction occurs before the electron source hits the bolus [34]. When the photon energy is given, a higher level of energy radiated will increase the maximum depth dose and decrease the surface dose. It was also seen that with the addition of boluses for photon energies of 6 and $10 \mathrm{MV}$, the maximum dose shifted towards the surface. This is in accordance with previous research conducted by Park et al., comparing the usage of Superflab bolus and $3 \mathrm{D}$ bolus above the Rando phantom without a bolus. The results show that bolus can change the build-up position on the PDD chart and increase the surface dose effectively [40].

On the other hand, Sroka et al., reported that the depth of $d_{\max }$ shifted to a higher depth in phantom due to the range of secondary electrons in the air which was almost three times for a $15 \mathrm{MV}$ photon beam compared to $6 \mathrm{MV}$ [41]. The same thing is also seen in Figure 4.

One of the bolus requirements is that the material can increase the dose to the surface [12, $13,15,21,24,34,40]$. A similar study was conducted by Chung et al., measuring the percentage of surface dose (PSD) with different bolus thicknesses at 6 and $15 \mathrm{MV}$ photon energies. PSD increased to $96.5-97.8 \%$ and 77.6$85.4 \%$, respectively for different plane sizes of 6 and $15 \mathrm{MV}$ photons for boluses with a thickness of $1 \mathrm{~cm}$ [42]. In addition, this increase in the percentage of the surface dose is due to differences in scattering that occur when electrons pass through the medium. Electron beam with low energy will be scattered more easily when interacting with the medium. The ratio percentage of the surface dose toward a depth dose maximum for lower-energy electrons is less than compared to higher-energy electrons $[28,34]$

\section{Conclusion}

In general, we demonstrated dosimetric properties of handmade boluses for megavoltage electron and photon radiation therapy. All of the synthesized boluses had a relative density electron (RED) in a group of soft tissues such as fat, water, breasts, and muscles. The use of bolus material can increase the percentage of surface doses at all energies. When the comparison the synthesized boluses such as 
natural rubber, paraffin wax, and the mixture of silicone with aluminum or bismuth to boluses commonly used in hospitals in Indonesia such as play-doh and red plasticine, the synthesized bolus from the mixture of silicone and aluminum has an opportunity to be used clinically because of material availability for fabrication and its economic value. Overall, the synthesized boluses have a potential for radiation therapy since all of the materials can be used as a tissue substitute and as an alternative in the treatment of superficial cancers using megavoltage electron and photon radiation therapy.

\section{Acknowledgment}

Authors thanks to the management of MRCCC Siloam Hospitals Semanggi, Jakarta, Indonesia, who has allowed us to do the research in the Radiotherapy Facility.

\section{Authors' Contribution}

Endarko was involved in the conceptualization and writing the original draft preparation, and reviewing/editing; Endarko, Siti Aisyah, Chycilia Clara Chandra Carina, Trimawarti Nazara, and Gandes Sekartaji were involved in the investigation, methodology, samples preparation, data collection, and visualization. Andreas Nainggolan was involved in clinical planning, methodology, and data collection. All the authors read, modified, and approved the final version of the manuscript.

\section{Conflict of Interest}

None

\section{References}

1. Khan Y, Villarreal-Barajas JE, Udowicz M, et al. Clinical and Dosimetric Implications of Air Gaps between Bolus and Skin Surface during Radiation Therapy. J Cancer Ther. 2013;4(7):1251-5. doi: 10.4236/jct.2013.47147.

2. Park K, Park S, Jeon MJ, Choi J, et al. Clinical application of 3D-printed-step-bolus in post-totalmastectomy electron conformal therapy. Oncotarget. 2017;8(15):25660-8. doi: 10.18632/oncotarget.12829. PubMed PMID: 27784001. PubMed PMCID: PMC5421959.

3. Malaescu I, Marin CN, Spunei M. Comparative Study on the Surface Dose of Some Bolus Materials. Int J Med Phys Clin Eng Radiat Oncol. 2015;4(4):348-52. doi: 10.4236/ijmpcero.2015.44041.

4. Dipasquale G, Poirier A, Sprunger $Y$, et al. Improving 3D-printing of megavoltage $X$-rays radiotherapy bolus with surface-scanner. Radiat Oncol. 2018;13(1):203. doi: 10.1186/s13014-018-1148-1.

5. Kudchadker RJ, Antolak JA, Morrison WH, et al. Utilization of custom electron bolus in head and neck radiotherapy. J Appl Clin Med Phys. 2003;4:321-33. doi: 10.1120/jacmp.v4i4.2503.

6. Kim MM, Kudchadker RJ, Kanke JE, et al. Bolus electron conformal therapy for the treatment of recurrent inflammatory breast cancer: A case report. Med Dosim. 2012;37(2):208-13. doi: 10.1016/j.meddos.2011.07.004. PubMed PMID: 21978532.

7. Supratman AS, Sutanto $H$, Hidayanto $E$, et al. Characteristic of natural rubber as bolus material for radiotherapy. Mater Res Express. 2018;5(9):95302. doi: 10.1088/2053-1591/aad5ca.

8. Humphries SM, Boyd K, Cornish P, Newman FD. Comparison of super stuff and paraffin wax bolus in radiation therapy of irregular surfaces. Med Dosim. 1996;21(3):155-7. doi: 10.1016/0958-3947(96)000763. PubMed PMID: 8899680.

9. Günhan B, Kemikler G, Koca A. Determination of surface dose and the effect of bolus to surface dose in electron beams. Med Dosim. 2003;28(3):193-8. doi: 10.1016/S0958-3947(03)00072-4. PubMed PMID: 14563440.

10. Kong Y, Yan T, Sun Y, Qian J, Zhou G, Cai S, et al. A dosimetric study on the use of 3D-printed customized boluses in photon therapy: A hydrogel and silica gel study. J Appl Clin Med Phys. 2019;20(1):348-55. doi: 10.1002/acm2.12489. PubMed PMID: 30402935. PubMed PMCID: PMC6333182.

11. Butson MJ, Cheung T, Yu P, Metcalfe P. Effects on skin dose from unwanted air gaps under bolus in photon beam radiotherapy. Radiat Meas. 2000;32(3):201-4. doi: 10.1016/S1350-4487(99)00276-0.

12. Jaya GW, Sutanto $H$. Fabrication and characterization of bolus material using polydimethyl-siloxane. Mater Res Express. 2018;5(1):15307. doi: 10.1088/20531591/aaa447.

13. Vyas V, Palmer L, Mudge R, Jiang $R$, et al. On bolus for megavoltage photon and electron radiation therapy. Med Dosim. 2013;38:268-73. doi: 10.1016/j.meddos.2013.02.007. PubMed PMID: 23582702.

14. Sutanto H, Marhaendrajaya I, Jaya GW, et al. The Properties of Bolus Material using Silicone Rubber. IOP Conference Series: Materials Science and Engineering, 3rd Materials Research Society of Indonesia Meeting (MRS-Id 2018); Bali, Indonesia: IOP Publishing; 2018.

15. Rancangkapti N, Hariyanto AP, Mariyam FU, et al. Dosimetry analysis of homemade bolus using propylene glycol for photon MegaVoltage and electron radiation therapy. Journal of Physics: Conference Series. 2019;1248:1-6. 
16. Huang K-M, Hsu C-H, Jeng S-C, Ting L-L, et al. The application of Aquaplast Thermoplastic as a bolus material in the radiotherapy of a patient with classic Kaposi's sarcoma at the lower extremity. Anticancer Res. 2006;26(1B):759-62. PubMed PMID: 16739350.

17. Adamson JD, Cooney T, Demehri F, et al. Characterization of Water-Clear Polymeric Gels for Use as Radiotherapy Bolus. Technol Cancer Res Treat. 2017;16(6):9239. doi: 10.1177/1533034617710579. PubMed PMID: 28554255. PubMed PMCID: PMC5762050.

18. Visscher S, Barnett E. Comparison of Bolus Materials to Highly Absorbent Polypropylene and Rayon Cloth. J Med Imaging Radiat Sci. 2017;48(1):5560. doi: 10.1016/j.jmir.2016.08.003. PubMed PMID: 31047211.

19. Barnett E, Le K, Surendra V, Visscher S, Wong J. Comparison of Bolus Materials vs Highly Absorbent Polypropylene and Rayon Cloth. J Med Imaging Radiat Sci. 2015;46(1):S19-S. doi: 10.1016/j.jmir.2015.01.061. PubMed PMID: 31047211.

20. Seppälä T, Collan J, Auterinen I, Serén T, et al. A dosimetric study on the use of bolus materials for treatment of superficial tumors with BNCT. Appl Radiat Isot. 2004;61(5):787-91. doi: 10.1016/j.apradiso.2004.05.054. PubMed PMID: 15308145.

21. Nagata K, Lattimer JC, March JS. The electron beam attenuating properties of superflab, play-doh, and wet gauze, compared to plastic water. Vet Radiol Ultrasound. 2012;53(1):96-100. doi: 10.1111/j.17408261.2011.01866.x. PubMed PMID: 22092982.

22. Segura T, Burillo G. Radiation modification of silicone rubber with glycidylmethacrylate. Radiat Phys Chem. 2013;91:101-7. doi: 10.1016/j.radphyschem.2013.06.011.

23. Rahimi A, Mashak A. Review on rubbers in medicine: Natural, silicone and polyurethane rubbers. Plast Rubber Compos. 2013;42:223-30. doi: 10.1179/1743289811Y.0000000063.

24. Montaseri A, Alinaghizadeh M, Mahdavi SR. Physical properties of ethyl methacrylate as a bolus in radiotherapy. Iran J Med Phy. 2012;9(2A):127-34. doi: 10.22038/ijmp.2012.318.

25. IAEA. Dosimetry and Medical Radiation Physics Section. News IAEA TRS 398; Vienna, Austria: IAEA; 2006.

26. Tagoe SNA, Mensah SY, Fletcher JJ, Sasu E. Telecobalt machine beam intensity modulation with aluminium compensating filter using missing tissue approach. Iranian Journal of Medical Physics. 2018;15(1):48-61. doi: 10.22038/ijmp.2017.23548.1253.

27. Hariyanto AP, Mariyam F, Almira L, Endarko E, Bambang S. Fabrication and Characterization of Bolus Material Using Propylene Glycol for Radiation Therapy. Iranian Journal of Medical Physics. 2020;17(3):161-9. doi: 10.22038/IJMP.2019.39798.1537.

28. Khan FM, Gibbons JP. The Physics of Radiation Therapy, 5 ed. USA: Lippincott Williams \& Wilkins, a Wolt- ers Kluwer business; 2014.

29. Saw CB, Loper A, Komanduri K, Combine T, et al. Determination of CT-to-density conversion relationship for image-based treatment planning systems. Medical Dosim. 2005;30(3):145-8. doi: 10.1016/j.meddos.2005.05.001. PubMed PMID: 16112465.

30. Binti F, Lothfy A. Durian Seed as a Potential Substrate for Bolus in Radiotherapy. Universiti Sains Malaysia; 2015.

31. Boskey AL. Bone composition: relationship to bone fragility and antiosteoporotic drug effects. BoneKEy Report. 2013;2(447):1 - 11. doi: 10.1038/ bonekey.2013.181.

32. ICRU. Tissue substitutes in radiation dosimetry and measurement: International Commission on Radiation Units and Measurements. ICRU (Report 44); 1989.

33. Walker M, Cohen N, Menchaca D. Play-Doh® and water-soaked gauze sponges as alternative bolus material for cobalt-60 teletherapy. Vet Radiol UItrasound. 2005;46(2):179-81. doi: 10.1111/j.17408261.2005.00033.x. PubMed PMID: 15869164.

34. Podgorsak EB. Radiation Oncology Physics: A Handbook for Teachers and Students. Austria: IAEA; 2005.

35. Navitha M, Nigam J, Silambarasan NS, Kumar P, Kumar P. Comparison of Electron Beam Transmission of Different Energies with Two Different Block Materials at Different Placement Positions within The Applicator. SRMS J Med Sci. 2016;1(2).

36. Kim SJ, Lee SJ, Moon SH, Seol KH, Lee JE. Characteristics of Photon Beam through a Handmade Build-Up Modifier as a Substitute of a Bolus. Prog Med Phys. 2014;25(4):225. doi: 10.14316/pmp.2014.25.4.225.

37. Paliwal BR, Rommelfanger S, Das RK. Attenuation characteristics of a new compensator material: Thermo-Shield for high energy electron and photon beams. Med Phys. 1998;25(4):484-7. doi: 10.1118/1.598223.

38. Tanir AG, Ketenci FS, Bölükdemir MH. Usage of attenuation coeffcients of some tissue-equivalent materials. Turk J Phys. 2015;39(1):69-74. doi: 10.3906/ fiz-1406-10.

39. James Tremethick L. Characterisation of Dosimetry in Electron Radiotherapy under different Bolus Applications. Australia: RMIT University; 2012.

40. Park JW, Oh SA, Yea JW, Kang MK. Fabrication of malleable three-dimensional-printed customized bolus using three-dimensional scanner. PLoS One. 2017;12(5). doi: 10.1371/journal.pone.0177562.

41. Sroka M, Reguła J, Obodziec W. The influence of the bolus-surface distance on the dose distribution in the build-up region. Rep Prac Oncol Radiother. 2010;15(6):161-4. doi: 10.1016/j.rpor.2010.09.003.

42. Chung JB, Kim JS, Kim IA, Lee JW. Surface dose measurements from air gaps under a bolus by using a MOSFET dosimeter in clinical oblique photon beams. J Korean Phys Soc. 2012;61(7):1143-7. doi: 10.3938/ jkps.61.1143. 